\title{
Generalized anxiety disorder associated with individual work performance of Indonesian medical personnel during COVID-19 outbreak
}

\author{
Eko Sujadi ${ }^{1}$, Muhammad Fadhli ${ }^{2}$, Muhd. Odha Meditamar ${ }^{3}$, Dairabi Kamil ${ }^{4}$, Ahmad Jamin $^{5}$, Hengki \\ Yandri $^{6}$, Syaiful Indra ${ }^{7}$ \\ 1,3,4,5,6 Islamic Guidance and Counseling Department, State Islamic Institute of Kerinci, Indonesia \\ ${ }^{2}$ English Education Department, University of Bengkulu, Indonesia \\ ${ }^{7}$ Islamic Guidance and Counseling Department, State Islamic University of Ar Raniry, Indonesia
}

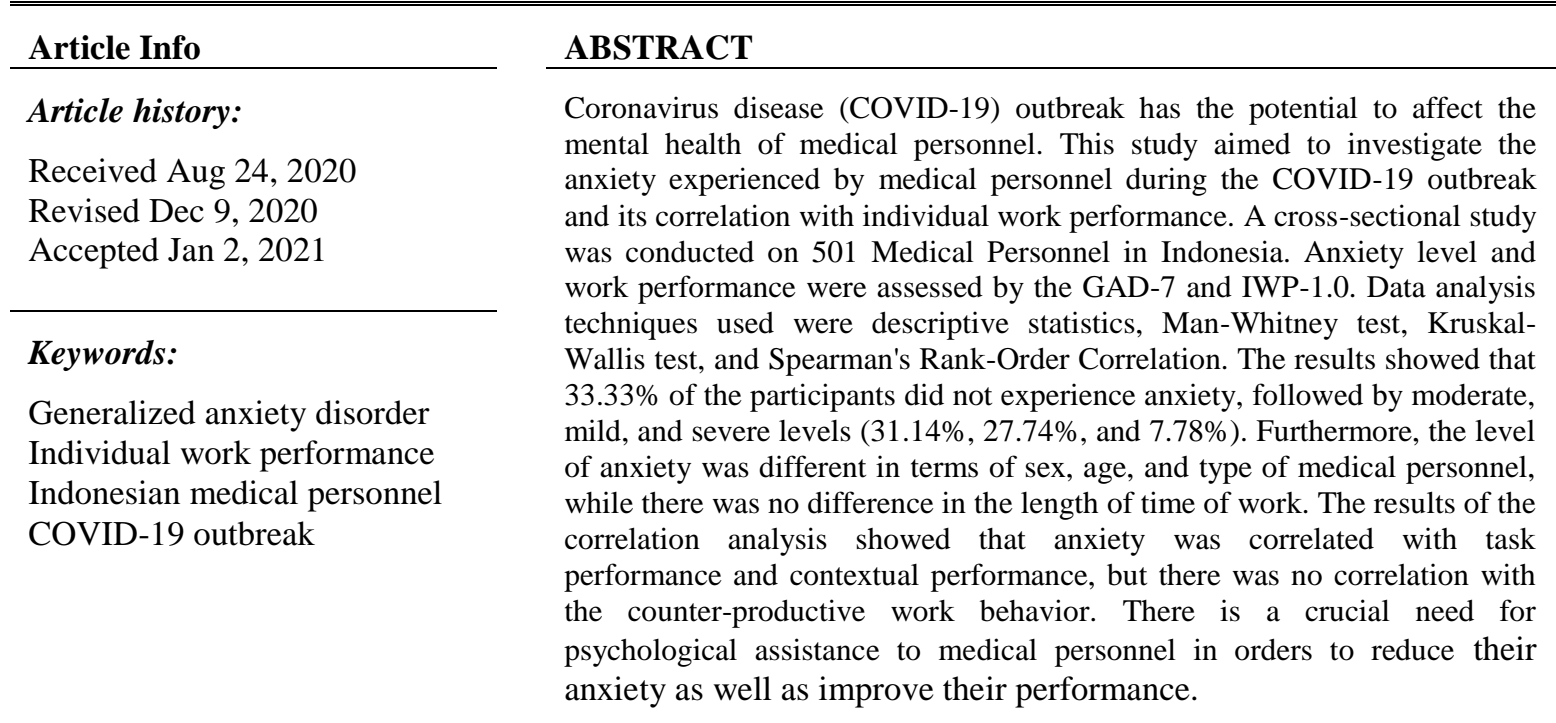

This is an open access article under the $\underline{C C B Y-S A}$ license.

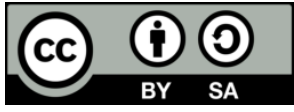

\section{Corresponding Author:}

Eko Sujadi

Department of Guidance and Counseling

State Islamic Institute of Kerinci

Kapten Muradi Street, Pesisir Bukit Sub-District, 37112, Jambi Province, Indonesia

Email: ekosujadi@iainkerinci.ac.id

\section{INTRODUCTION}

Nowadays, the world's attention is focused on handling COVID-19. This disease is confirmed as an acute respiratory infection caused by the novel Coronavirus [1], with symptoms including fever, fatigue, dry cough, dyspnea, with or without nasal congestion, runny nose or other upper respiratory symptoms [2]. Up to August 24, 2020 there are 23,057,288 confirmed cases with 800,906 confirmed death spread over 216 countries [3]. Due to the danger of this outbreak, on January 30, 2020 the WHO declared an international health emergency [4].

Inevitably, the outbreak of the virus caused a significant impact on many aspects, such as the economy, tourism, work, social, and Education. COVID 19 also causes people to experience mental health problems. Information broadcast by the media regarding the dangers of COVID-19 and the unavailability of a vaccine causes psychosomatic symptoms in the community. Especially in Indonesia, the panic over this 
outbreak in the early days caused other significant impacts, such as the lack of availability of masks and hand sanitizers $[5,6]$.

Anxiety can be experienced by each individual with varying intensities. Anxiety can be understood as a pathological part of normal fear, manifested by mood disorders such as thoughts, behavior and physiological activities [7]. Anxiety disorders (generalized anxiety disorder, agoraphobia, and social anxiety disorder) are the most common psychiatric disorders and are associated with a high burden of illness [8]. Anxiety disorders are often under recognized and not dealt with quickly [8]. A research reveals that generalized anxiety disorder causes the quality of life to decrease [9]. Besides, anxiety can also cause other health problems, such as heart disease [10]. Several dimensions of anxiety disorder include chronic, excessive and uncontrollable worry about multiple topics [11].

Several studies have shown that COVID-19 has affected the anxiety of the general public and certain groups. This pandemic affects the psychological aspects of college students [12], teachers and students [13], presents a major mental health challenge to older adults [14], young adult [15], and internal migrant worker [16]. COVID-19 also has a significant impact on the anxiety of medical personnel [17-19].

A study revealed that nurses who co-treat COVID-19 patients showed stimulation/sensitivity, irritability, reluctance to rest, and signs of psychological disorders, but refuse psychological help and claim that they do not have any problems [20]. Medical personnel are also concerned about a lack of personal protective equipment, as well as a feeling of being unable to treat critical patients [20]. They face a high level of stress, including a high risk of contracting, overwork, frustration, discrimination, isolation, dealing with patients with negative emotions, intense family relationships, and fatigue [21]. It is predicted that this anxiety disorder can interfere with the work performance of health workers, especially when dealing with COVID-19 patients.

Several studies reveal that the anxiety experienced by workers has a correlation with several dimensions of work performance [22-25]. Work performance consists of explicit job behavior that includes the fundamental job responsibilities assigned as part of the job description [26]. Performance standards are set based on job criteria that explain what the organization has given its employees to do, therefore individual performance in job criteria must be measured, compared with existing standards and the results must be notified to all employees. Several aspects of work performance were expressed by several experts, including creativity, reactivity in the face of difficulties, interpersonal adaptability, training efforts, and handling workrelated stress. In addition, other concepts also mention aspects of task performance, contextual performance, and counter-productive work behavior [27]. Task performance is an individual's proficiency in performing core or technical tasks in his job [28]; contextual performance is behavior that supports the organizational, social and psychological environment in which the technical core must function [29]; on the other hand, counterproductive work behavior is behavior that harms the well-being of the organization [30]. These three dimensions then form the basis for preparing the Individual Work Performance questionnaire [27].

Currently, it is very important to know in detail about the anxiety experienced by medical personnel, so that it can be used as a basis for psychological intervention on them. In particular, this study aimed to: 1) evaluate the anxiety experienced by medical personnel when dealing with COVID-19;2) as a theoretical basis for providing psychological intervention to medical personnel; 3) as material for policy making by the government related to improving the mental health of medical personnel.

\section{RESEARCH METHOD}

\subsection{Study design and participants}

A cross-sectional survey used in this study aimed to measure anxiety and individual work performance of health workers from June 17, 2020 to July 25, 2020. Participants in this study were medical personnel in Indonesia who were handling suspected and confirmed COVID-19 cases, which are classified into three groups, namely doctors, nurses, and other health workers (midwifery personnel, pharmaceutical technical personnel, biomedical engineering personnel). A total of 501 participants participated in filling out this questionnaire. Table 1 shows the demographic and other special characteristics.

Demographic characteristics and other special characteristics can be seen in Table 1. Women who participated in filling out this questionnaire were $57.5 \%$, while men were $42.5 \%$; Furthermore, in the age factor, the most participating age groups were 21-25 (45.5\%), followed by the 26-35, 36-45 and 46-55 age groups, respectively $41.5 \%, 10.8 \%$ and $2.2 \%$; On the characteristics of the type of workforce, nurses dominate $41.9 \%$, followed by doctors and other health workers $(37.5 \%$ and $20.6 \%)$; on the characteristics of the length of work, more dominated by health workers whose work period was <4 years $(59.9 \%)$, then sequentially 4-8 years, 9-13 years, 14-18 years, 19-23 years and >23 years, namely $22.3 \%, 10.0 \%, 5.2 \%$, $1.4 \%$ and $1.2 \%$; lastly, $51.90 \%$ of participants worked at referral hospitals for COVID-19 patients, while $48.10 \%$ of participants worked for hospitals or clinics that were not a referral for COVID-19 patients.

Int. J. Public Health Sci. Vol. 10, No. 1, March 2021: 207 - 214 
Table 1. Demographic characteristics and specific characteristics of participants

\begin{tabular}{cccc}
\hline Variable & Category & Frequency & Percentage \\
\hline \multirow{2}{*}{ Gender } & Male & 213 & 42.51 \\
& Female & 288 & 57.48 \\
\multirow{3}{*}{ Age } & $21-25$ & 228 & 45.51 \\
& $26-35$ & 208 & 41.52 \\
& $36-45$ & 54 & 10.79 \\
Types of medical personnel & $46-55$ & 11 & 2.19 \\
& Doctor & 188 & 37.52 \\
& Nurse & 210 & 41.92 \\
length of working experience & Other medical personnel & 103 & 20.56 \\
& Less than 4 Years & 300 & 59.88 \\
& $4-8$ Years & 112 & 22.36 \\
& $9-13$ Years & 50 & 9.98 \\
& $14-18$ Years & 26 & 5.19 \\
& $19-23$ Years & 7 & 1.40 \\
& More than 23 Years & 6 & 1.20 \\
& A referral for COVID-19 patients & 260 & 51.90 \\
& Not a referral for COVID-19 patients & 241 & 48.10 \\
\hline
\end{tabular}

\subsection{Instruments}

\subsubsection{Generalized anxiety disorder scale (GAD-7)}

The Generalized Anxiety Disorder Scale (GAD-7) used in this study aimed to measure the anxiety experienced by participants. This instrument measures the anxiety symptoms experienced by participants related to COVID-19 in the past two weeks. GAD-7 consists of seven items using four Likert scale options, namely $0=$ not at all, $1=$ several days, $2=$ more than half the days, and $3=$ nearly every day. GAD -7 norms are interpreted as: minimal (0-4), mild (5-9), moderate (10-14) and severe (14-20). This scale is reported to be reliable and valid for measuring anxiety in both general and special groups [31,32]. We use this scale in the Indonesian version. Internal validity and reliability for Indonesian version of GAD-7 were satisfactory with validity coefficient of 0.648 to $0.800(\mathrm{p}<0.01)$ and Cronbach's alpha value of 0.867 [32].

\subsubsection{Individual work performance questionnaire}

In this study, Work performance was measured using the Individual Work Performance Questionnaire (IWP-1.0) [33]. This questionnaire consists of 18 items. All items had a recall period of 3 months. This scale consists of 3 dimensions, namely task performance (TP) consisting of 5 items, contextual performance (CP) consisting of 8 items and counterproductive work behavior (CWB) consisting of eight items [33]. This questionnaire uses a five-choice Likert scale (TP and CP: seldom, sometimes, regularly, often, always; CWB: never, seldom, sometimes, regularly, often). This questionnaire has a high coefficient of reliability and validity; the reliability coefficient for task performance is 0.78 , contextual performance is 0.85 , and counter-productive work behavior is 0.79 [34].

\subsection{Statistical analysis}

All data were analyzed using IBM SPSS version 24. Descriptive statistics (frequency, percentages, mean, and standard deviation) were used to describe general health worker anxiety as well as based on demographic and other special characteristics. Multivariate analysis of health worker anxiety in terms of gender using the Man-Whitney test, while Kruskal-Wallis are used to reveal differences in anxiety in terms of other characteristics. Furthermore, Spearman's Rank-Order Correlation is used to determine the relationship between generalized anxiety disorder and individual dimensions of work performance (task performance, contextual performance, and counterproductive work behavior).

\section{RESULTS AND DISCUSSION}

\subsection{Results}

Table 2 shows that $33.33 \%$ of participants did not experience anxiety disorders (minimal), then $31.14 \%$ of participants experienced moderate levels of anxiety disorder, followed by mild and severe levels of $27.74 \%$ and $7.78 \%$. Furthermore, Table 3 explains the differences in anxiety in terms of gender, age, type of medical personnel, and length of work experience. The results of the analysis show that: 1) there is a difference in anxiety in terms of gender $(\mathrm{p}<.000)$, where the average score of women's anxiety is higher than that of men with an average score of 8.43 and 6.47. 2) there is a difference in anxiety in terms of age $(\mathrm{p}<0.009)$. Table 2 shows that the highest level of anxiety was experienced by medical personnel aged 21-25 with an average score of 8.40, while the lowest level of anxiety was experienced by the 46-45 age group. 3) 
there are differences in anxiety between doctors, nurses and other medical personnel $(\mathrm{p}<0.017)$; The highest level of anxiety was experienced by nurses with an average score of 8.50 , followed by doctors and other health workers (midwifery staff, pharmaceutical technicians, biomedical engineering workers) at 7.21 and 6.67 , respectively. 4) There is no difference in anxiety seen from the length of work experience $(\mathrm{p}>0.222)$. However, medical personnel whose work tenure is less experienced a higher level of anxiety than those who have worked for a long time. 5) There is a difference in anxiety between medical personnel who work at referral hospitals for COVID-19 patients and medical personnel who work in hospitals or clinics that are not referrals for COVID-19 patients $(\mathrm{p}<0.000)$; medical personnel who work at referral hospitals for COVID-19 patients experience higher anxiety.

Table 2. Respondents with different anxiety level $(n=501)$

\begin{tabular}{ccccc}
\hline Anxiety level & Number of participants & Percentage $(\%)$ & Mean & Standard deviation \\
\hline Minimal & 167 & 33.33 & 1.63 & 1.40 \\
Mild & 139 & 27.74 & 7.11 & 1.36 \\
Moderate & 156 & 31.14 & 12.33 & 1.43 \\
Severe & 39 & 7.78 & 16.51 & 1.29 \\
\hline
\end{tabular}

Table 3. Univariate analysis of health workers' anxiety about the COVID-19 outbreak

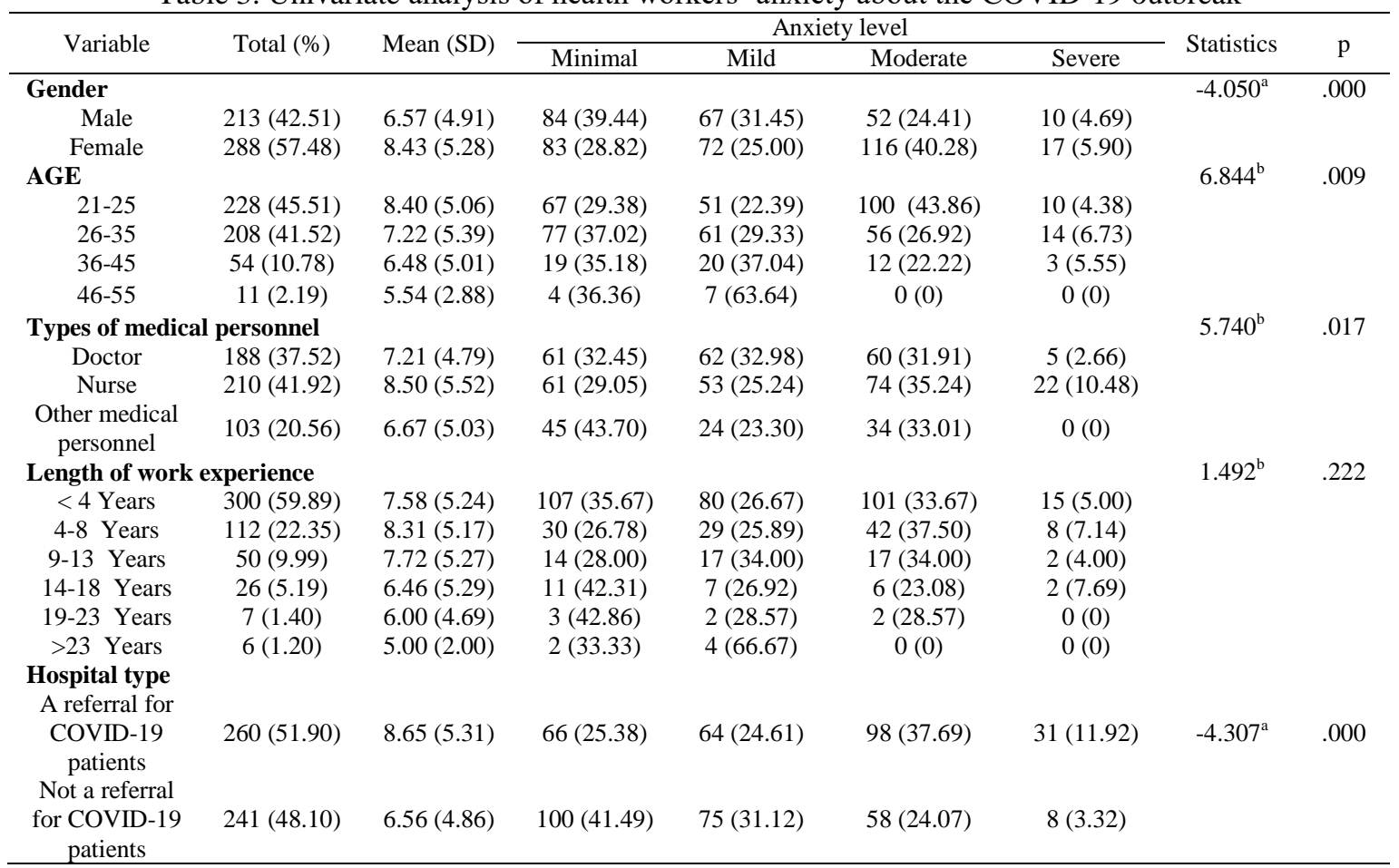

a. Mann-Whitney test

b. Kruskal-Wallis test

The results of the correlation analysis between generalized anxiety disorders experienced by medical personnel in Indonesia with the individual dimensions of work performance are shown in Table 4. Anxiety has a negative correlation with task performance $(\mathrm{r}=-133)$ and contextual performance $(\mathrm{r}=-.103)$, while the correlation with the dimensions of counter-productive work behavior $(\mathrm{r}=-.060)$ was not found.

Table 4. Correlation between generalized anxiety disorder and individual dimensions of work performance (task performance, contextual performance, counter-productive work behavior)

\begin{tabular}{cccc}
\hline & \multicolumn{3}{c}{ Individual work performance dimensions } \\
\cline { 2 - 4 } & Task & Contextual & Counter productive work \\
performance & performance & $-.103^{*}$ & -.060 \\
GAD & $-.133^{*}$ & &
\end{tabular}




\subsection{Discussion}

Anxiety during the COVID-19 outbreak is experienced by both the general and specific population. A survey on general public anxiety about COVID-19 in America, found that $48 \%$ of participants were worried about contracting COVID-19 and 59\% stated that COVID-19 was affecting their lives [35]. Another study revealed that more than $50 \%$ of participants experienced anxiety and psychological distress during this pandemic [36]. One of the causes of public anxiety regarding COVID-19 is due to the almost constant flow of news about COVID-19. Therefore, WHO recommends avoiding news about COVID-19 that makes you uncomfortable, especially hoax news about COVID-19 [37].

The results of this study indicated that $31.14 \%$ of medical personnel experienced a moderate level of anxiety, followed by mild and severe levels, namely $27.74 \%$ and $7.78 \%$; relevant to the findings of previous studies which revealed that medical personnel experience anxiety during this pandemic [17-19]. The anxiety experienced during the COVID-19 outbreak by medical personnel has been mixed. In comparison, a study of health workers in Peru showed greater anxiety, with $21.7 \%$ of medical personnel experienced severe anxiety during this outbreak. [18]. However, there are studies which reveal that only a small proportion of medical personnel experience extremely severe anxiety [19]. Participants who experienced moderate and severe levels of anxiety generally worked at referral hospitals for COVID-19 patients in Indonesia, while participants who were at a mild level were those who worked in hospitals, health centers, and health clinics who did not directly handle COVID-19 patients, but still has the potential to become the first health center visited by patients with symptoms of COVID-19. This findings may indeed be relevant to previous studies that found that medical personnel employed in the outpatient pandemic clinic + pandemic department experience greater anxiety than medical personnel employed only in the outpatient pandemic clinic or department [38].

The anxiety experienced by medical personnel is because they have the potential to contract COVID-19 from patients. Even some cases of death due to COVID-19 have come from medical personnel. As of July 20, 2020, 821 health workers in America have died from COVID-19 [39]; The Indonesian Doctors Association also reported that 68 doctors died [40], this does not include other medical personnel. Many sacrifices have been made by medical personnel in helping the handling of COVID-19 patients, such as experiencing facial wounds due to using N95 masks for too long, using diapers while working, not eating and drinking to save personal protective equipment, even among health workers who cut their hair in order to reduce the risk of contracting it. In the absence of personal protective equipment, the number of tasks that must be completed, facing various patient characteristics, isolation, etc., they are still required to perform high work performance.

The univariate analysis shows that there are differences in medical personnel anxiety in terms of gender, in which women experience higher anxiety than men; these findings support previous research [41, 42]. Female consistently has a higher prevalence of anxiety disorders, but little is known about how gender affects age of onset, chronicity, comorbidity, and burden of illness [43]. In women, generalized anxiety disorder (GAD) has a positive correlation with depression symptoms and loneliness, while in men it has correlation with somatic symptoms [44]. Anxiety also differed significantly in terms of age. The participants who filled out this questionnaire consisted of several age groups. Starting from those who have just entered the world of work to enter retirement. These findings indicate that anxiety is highest in the 21-25 age group, followed by the $26-35,36-45$ and $46-55$ age groups. Several studies have shown that younger individuals show symptoms of anxiety than older people [18, 41, 45]; supported by the finding that older person has a lower current and lifetime social anxiety disorder [46].

In terms of the type of medical personnel (doctors, nurses and other medical personnel), nurses obtained a higher anxiety score than doctors and other medical personnel; relevant to previous research [47]. A study shows there is a difference in anxiety between medical staff and other medical workers [48]. The same result was revealed through a study that compared to doctors, nurses were under higher pressure in handling COVID-19 [49]. In this study, only the characteristics of the length of work experience did not determine the differences in anxiety among participants; these findings support other studies [50]. However, the scores for medical personnel who worked $<8$ years were higher than those who had worked longer hours. As a comparison, one of the causes of the higher anxiety symptoms experienced by young doctors is direct exposure and longer working hours; senior doctors act as advisors and main administrative responsibility, so there is less contact with COVID-19 patients [51]. However, this condition is not always the same between hospitals and countries.

The results of the correlation analysis show a negative relationship between anxiety and the two dimensions of individual work performance (task performance and contextual performance), while there is no correlation with the dimensions of counter-productive work behavior. Individual work performance is a multidimensional construct. Of these three constructs, there are two positive dimensions, namely task performance (TP) and contextual performance (CP), while counter-productive work behavior (CWB) is a 
behavior that hinders organizational goals. The lower the anxiety experienced by the participants, the higher the TP and CP dimensions, and vice versa. This supports research which reveals that contextual performance is closely related with burnout [22]; In relation to CT, Individuals with GAD evidenced impaired performance on an attention vigilance task [23]. Previous researchers have also investigated the relationship between mental health and counter work behavior. A study revealed that job stress is correlated with CWB [24]. Stress conditions are specifically associated with negative emotions, aggression and CWB [52]. This is supported by other findings which say that pressure at work can not only cause CWB, but also cause negative employee effectiveness [25].

The current condition demands that every medical personnel receive intensive attention, especially from the government, such as the provision of physical facilities, personal protective equipment, psychological intervention, providing nutritious food, rest time arrangements, incentives, and support from those closest to them. Barriers such as high anxiety in dealing with COVID-19 patients must be reduced so that work performance is good. Barriers to implementing workplace practices can weaken employee commitment to the organization which is positively related to work performance.

There were several limitations to our study. First, this measurement was carried out by cross sectional without any follow-up through a longitudinal study. The case of COVID-19 which continues to experience changes may have an impact on changes in the anxiety conditions experienced by health workers. In addition, data on the anxiety experienced by medical personnel prior to the COVID-19 outbreak were not available, making it difficult to know whether the anxiety conditions they were experiencing were influenced by conditions before the outbreak. Second, this questionnaire is self-assessment, so it may differ from psychological assessments conducted by professionals. Third, the questionnaire was distributed through WhatsApp groups with members of medical personnel in Indonesia. We still have difficulty getting data from medical personnel in eastern Indonesia; Besides that, difficulties were also experienced when they wanted to collect data from specialist doctors who were busy handling COVID-19 patients.

\section{CONCLUSION}

Medical personnel have felt anxiety during the COVID-19 outbreak, especially those who are treating positive patients. This increase in cases is predicted to have an effect on the increase in the number of health workers experiencing mental health problems, especially since there are still many health facilities that do not meet standards, unavailability of vaccines, scarcity of personal protective equipment, lack of rest time, and strict activity rules for them. Of course, these problems will affect work performance. Based on this condition, psychological intervention is needed for medical personnel who are in charge of handling COVID19 patients, providing complete health facilities and personal protective equipment, and most importantly finding a vaccine for this disease as soon as possible.

\section{ACKNOWLEDGEMENTS}

We express our deepest gratitude to all respondents who are willing to fill out the instruments that have been distributed. Furthermore, we also thank all those who contributed to the COVID-19 countermeasures.

\section{REFERENCES}

[1] D. Wu, T. Wu, Q. Liu, Z. Yang, “The SARS-CoV-2 outbreak: what we know," International Journal Infectious Disease, vol. 94, pp. 44-48, 2020, doi: 10.1016/j.ijid.2020.03.004.

[2] S. R. Weiss and J. L. Leibowitz, "Coronavirus pathogenesis," Advances Virus Research, vol. 81, pp. 85-164, 2011, doi: 10.1016/B978-0-12-385885-6.00009-2.

[3] WHO, "Coronavirus disease (COVID-19) outbreak situation," 2020. [Online]. Available: https://www.who.int/emergencies/diseases/novel-coronavirus-2019.

[4] C. Sohrabi, et al., "World Health Organization declares global emergency: A review of the 2019 novel coronavirus (COVID-19)," Int. J. Surg., vol. 76, pp. 71-76, 2020, doi: 10.1016/j.ijsu.2020.02.034.

[5] R. Djalante, et al., "Review and analysis of current responses to COVID-19 in Indonesia: Period of January to March 2020," Prog. Disaster Sci., vol. 6, p. 100091, 2020, doi: https://doi.org/10.1016/j.pdisas.2020.100091.

[6] R. Rahman, M. A. Iswara, Y. Prasidya, "Staple foods safe, but masks, sanitizer gone from markets as consumer behavior shifts," The Jakarta Post, Jakarta, 2020.

[7] A. Adwas, J. Jbireal, and A. Azab, "Anxiety: Insights into Signs, Symptoms, Etiology, Pathophysiology, and Treatment," South African Journal Medical Sciences, vol. 2, no. 10, pp. 80-91, Oct. 2019.

[8] D. Wedekind, B. Bandelow, "Trends in the treatment of anxiety disorders," Psycho Neurology, vol. 31, no. 10, pp. 499-503, 2005. 
[9] T. L. Barrera, P. J. Norton, "Quality of life impairment in generalized anxiety disorder, social phobia, and panic disorder," Journal of Anxiety Disorders, vol. 23, no. 8, pp. 1086-1090, Dec. 2009, doi: 10.1016/j.janxdis.2009.07.011.

[10] R. C. Day, K. E. Freedland, R. M. Carney, "Effects of anxiety and depression on heart disease attributions," International Journal of Behavioral Medicine, vol. 12, no. 1, pp. 24-29, 2005, doi: 10.1207/s15327558ijbm1201_4.

[11] C. C. Bell, "DSM-IV: Diagnostic and Statistical Manual of Mental Disorders," JAMA, vol. 272, no. 10, pp. 828829, 1994, doi: 10.1001/jama.1994.03520100096046.

[12] W. Cao, et al., "The psychological impact of the COVID-19 epidemic on college students in China," Psychiatry Research, vol. 287, 2020, doi: 10.1016/j.psychres.2020.112934.

[13] E. Sujadi, et al., "An Anxiety Analysis of Educators, Students and Parents Facing the New Normal Era in Education Sector in Indonesia," Asian Journal Psychiatry, vol. 53, 2020, doi: https://doi.org/10.1016/j.ajp.2020.102226.

[14] Y. T. Yang, et al., "Mental Health Services for Older Adults in China During the COVID-19 Outbreak," Lancet Psychiatry, vol. 7, no. 4, p. e19, 2020, doi: 10.1016/S2215-0366(20)30079-1.

[15] C. H. Liu, E. Zhang, G. T. F. Wong., et al., "Factors associated with depression, anxiety, and PTSD symptomatology during the COVID-19 pandemic: Clinical implications for U.S. young adult mental health," Psychiatry Research, vol. 290, p. 113172, 2020, doi: https://doi.org/10.1016/j.psychres.2020.113172.

[16] R. Choudhari, "COVID 19 Pandemic: Mental health challenges of Internal migrant workers of India," Asian Journal Psychiatry, vol. 54, p. 102254, 2020, doi: https://doi.org/10.1016/j.ajp.2020.102254.

[17] N. W. S. Chew, et al., "A multinational, multicentre study on the psychological outcomes and associated physical symptoms amongst healthcare workers during COVID-19 outbreak," Brain, Behav, Immun, vol. 88, pp. 559-565, 2020, doi: https://doi.org/10.1016/j.bbi.2020.04.049.

[18] J. A. Yáñez, A. A. Jahanshahi, A. Alvarez-Risco, J. Li, and S. X. Zhang, "Anxiety, Distress, and Turnover Intention of Healthcare Workers in Peru by Their Distance to the Epicenter during the COVID-19 Crisis," American Journal Tropical Medicine Hygiene, vol. 103, no. 4, pp. 1614-1620, 2020, doi: https://doi.org/10.4269/ajtmh.20-0800.

[19] D. Nasrullah, et al., "The Psychological Impact Among Health Workers In Effort To Facing The COVID-19 In Indonesia," International Journal Public Health Sciences, vol. 10, no. 1, 2020, doi: http://doi.org/10.11591/ijphs.v10i1.20524.

[20] Q. Chen et al., "Mental health care for medical staff in China during the COVID-19 outbreak," The Lancet Psychiatry, vol. 7, no. 4, pp. e15-e16, 2020, doi: 10.1016/S2215-0366(20)30078-X.

[21] C. Wang, P. W. Horby, F. G. Hayden., et al., "A novel coronavirus outbreak of global health concern," Lancet, vol. 395, no. 10223, pp. 470-473, 2020, doi: 10.1016/S0140-6736(20)30185-9.

[22] P. Palenzuela, N. Delgado, J. Rodríguez, "Exploring the Relationship between Contextual Performance and Burnout in Healthcare Professionals," Revista de Psicología del Trabajo y de las Organizaciones, vol. 35, no. 2, pp. 115-121, Jan. 2019.

[23] P. M. Dibartolo, T. A. Brown, D. H. Barlow, "Effects of anxiety on attentional allocation and task performance: An information processing analysis," Behaviour Research and Therapy, vol. 35, no. 12, pp. 1101-1111, 1997, doi: https://doi.org/10.1016/S0005-7967(97)80004-6.

[24] S. Salami, "Job Stress and Counterproductive Work Behaviour: Negative Affectivity as a Moderator," Social Sciences, vol. 5, no. 6, pp. 486-492, Jun. 2010, doi: 10.3923/sscience.2010.486.492.

[25] L. Ma, W. Li, "The Relationship between Stress and Counterproductive Work Behavior: Attachment Orientation as a Moderate," Open Journal Social Sciences, vol. 7, no. 4, pp. 413-42, 2019, doi: https://doi.org/10.4236/jss.2019.74033.

[26] R. Pradhan, L. Jena, "Employee Performance at Workplace: Conceptual Model and Empirical Validation," Bus. Perspection Research, vol. 5, pp. 1-17, Dec. 2016, doi: 10.1177/2278533716671630.

[27] L. Koopmans, C. Bernaards, V. Hildebrandt., et al., "Construct Validity of the Individual Work Performance Questionnaire," Journal of Occupational and Environmental Medicine, vol. 56, no. 3, pp. 331-7, 2014, doi: 10.1097/JOM.0000000000000113.

[28] J. P. Campbell, "Modeling the performance prediction problem in industrial and organizational psychology.," Handbook of industrial and organizational psychology, vol. 1, 2nd ed., Palo Alto, CA, US: Consulting Psychologists Press, pp. 687-732, 1990.

[29] W. C. Borman, S., Motowildo, "Expanding the Criterion Domain to Include Elements of Contextual Performance," Personnel Selection in Organizations, N. Schmitt and W. C. Borman, Eds. 1993, pp. 71-98.

[30] M. Rotundo, P. R. Sackett, "The relative importance of task, citizenship, and counterproductive performance to global ratings of job performance: A policy-capturing approach.," Journal of Applied Psychology, vol. 87, no. 1. pp. 66-80, 2002, doi: 10.1037/0021-9010.87.1.66.

[31] R. L. Spitzer, et al., "A Brief Measure for Assessing Generalized Anxiety Disorder: The GAD-7," JAMA Internal Medicine, vol. 166, no. 10, pp. 1092-1097, May 2006, doi: 10.1001/archinte.166.10.1092.

[32] A. Budikayanti, A. Larasari, K. Malik., et al., "Screening of Generalized Anxiety Disorder in Patients with Epilepsy: Using a Valid and Reliable Indonesian Version of Generalized Anxiety Disorder-7 (GAD-7)," Neurology Research International, vol. 2019, no. 1, p. 5902610, 2019, doi: 10.1155/2019/5902610.

[33] L. Koopmans, et al., "Development of an Individual Work Performance Questionnaire," International Journal Productivity Performance Managements, vol. 62, pp. 6-28, Jan. 2013, doi: 10.1108/17410401311285273.

[34] L. Koopmans, "Individual work performance questionnaire: Instruction manual," VU Univ. Medical Center, 2015. 
[35] V. A. Canady, “APA poll finds nearly half anxious about getting COVID-19," Mental Health Wkly., vol. 30, no. 13, p. 5, 2020, doi: 10.1002/mhw.32295.

[36] M. B. Petzold et al., "Risk, resilience, psychological distress, and anxiety at the beginning of the COVID-19 pandemic in Germany," Brain Behav., vol. 10, no. 3, 2020, doi: 10.1002/brb3.1745.

[37] WHO, "Mental health and psychosocial considerations during COVID-19 Outbreak," World Heal. Organ., pp. 1-6, 2020.

[38] S. Korkmaz, A. Kazgan, S. Çekiç., et al., "The anxiety levels, quality of sleep and life and problem-solving skills in healthcare workers employed in COVID-19 services," Journal of Clinical Neuroscience, vol. 80, pp. 131-136, 2020, doi: https://doi.org/10.1016/j.jocn.2020.07.073.

[39] The Guardian and Kaiser Health News, "Covid-19 healthcare worker death toll: 821 deaths under investigation," The Guardian, 2020.

[40] B. Alam, "IDI: 68 Dokter Meninggal Dunia karena Covid-19," Liputan 6, 2020.

[41] Y. Huang and N. Zhao, "Generalized anxiety disorder, depressive symptoms and sleep quality during COVID-19 outbreak in China: a web-based cross-sectional survey," Psychiatry Research, vol. 288, pp. 112954, 2020, doi: https://doi.org/10.1016/j.psychres.2020.112954.

[42] D. Hu, et al., "Frontline nurses' burnout, anxiety, depression, and fear statuses and their associated factors during the COVID-19 outbreak in Wuhan, China: A large-scale cross-sectional study," The Lancet, vol. 24, p. 100424, 2020, doi: https://doi.org/10.1016/j.eclinm.2020.100424.

[43] N. C. Donner, C. A. Lowry, "Sex differences in anxiety and emotional behavior," Pflügers Arch. - Eur. J. Physiol., vol. 465, no. 5, pp. 601-626, 2013, doi: 10.1007/s00424-013-1271-7.

[44] F. H. Boehlen, et al., "Gender-specific predictors of generalized anxiety disorder symptoms in older adults: Results of a large population-based study," Journal Affective Disorder, vol. 262, pp. 174-181, 2020.

[45] G. A. Brenes, et al., "Age and racial differences in the presentation and treatment of generalized anxiety disorder in primary care," Journal Anxiety Disorder, vol. 22, no. 7, pp. 1128-1136, 2008, doi: 10.1016/j.janxdis.2007.11.011.

[46] A. J. Flint, et al., "Effect of age on the frequency of anxiety disorders in major depression with psychotic features," American Journal Geriatric psychiatry Official Journal AmAmerican Association Geriatric Psychiatry, vol. 18, no. 5, pp. 404-412, May 2010.

[47] Z. Zhu, et al., "COVID-19 in Wuhan: Sociodemographic characteristics and hospital support measures associated with the immediate psychological impact on healthcare workers," The Lancet, vol. 24, p. 100443, 2020, doi: https://doi.org/10.1016/j.eclinm.2020.100443.

[48] Q. Cai, et al., "The mental health of frontline and non-frontline medical workers during the coronavirus disease 2019 (COVID-19) outbreak in China: A case-control study," Journal Affective Disorder, vol. 275, pp. 210-215, 2020, doi: https://doi.org/10.1016/j.jad.2020.06.031.

[49] H. Wang, et al., "Healthcare workers' stress when caring for COVID-19 patients: An altruistic perspective," Nursing Ethics, vol. 27, no. 7, pp. 1490-1500, 2020, doi: 10.1177/0969733020934146.

[50] J. Lai, et al., "Factors Associated With Mental Health Outcomes Among Health Care Workers Exposed to Coronavirus Disease 2019," JAMA Netw. open, vol. 3, no. 3, pp. 1-12, 2020, doi: 10.1001/jamanetworkopen.2020.3976.

[51] S. Gupta, et al., "Psychological Health Among Armed Forces Doctors During COVID-19 Pandemic in India," Indian Journal of Psychological Medicine, vol. 42, no. 4, pp. 374-378, 2020, doi: 10.1177/0253717620934037.

[52] S. Fox, P. E. Spector, D. Miles, "Counterproductive work behavior (CWB) in response to job stressors and organizational justice: some mediator and moderator tests for autonomy and emotions," Journal Vocational Behavior, vol. 59, no. 3, pp. 291-309, 2001, doi: https://doi.org/10.1006/jvbe.2001.1803. 